\title{
Adaptations and responses of the common dandelion to low atmospheric pressure in high-altitude environments
}

\author{
Carla C. M. Arce ${ }^{1}$ (D) | Zoe Bont ${ }^{2}$ (D) | Ricardo A. R. Machado ${ }^{3}$ | Paulo F. Cristaldo ${ }^{4}$ (D) | \\ Matthias Erb' ${ }^{2}$ (D)
}

${ }^{1}$ Laboratory of Fundamental and Applied Research in Chemical Ecology, University of Neuchâtel, Neuchâtel, Switzerland

${ }^{2}$ Institute of Plant Sciences, University of Bern, Bern, Switzerland

${ }^{3}$ Experimental Biology Research Group, Institute of Biology, University of Neuchâtel, Neuchâtel, Switzerland

${ }^{4}$ Agronomy Department, Rural Federal University of Pernambuco, Recife, Brazil

\section{Correspondence}

Matthias Erb

Email: matthias.erb@ips.unibe.ch

Funding information

Schweizerischer Nationalfonds zur Förderung der Wissenschaftlichen Forschung, Grant/Award Number: 153517; Seventh Framework Programme, Grant/ Award Number: FP7 MC-CIG 629134

Handling Editor: Mizanur Rahman

\begin{abstract}
1. Atmospheric pressure is an important, yet understudied factor that may shape plant ecology and evolution.

2. By growing plants under controlled conditions at different experimental stations in the Swiss alps, we evaluated the impact of ecologically realistic atmospheric pressures between 660 and $950 \mathrm{hPa}$ on the growth and defence of different dandelion populations.

3. Low atmospheric pressure was associated with reduced root growth and defensive sesquiterpene lactone production. Defence suppression only occurred in populations originating from lower altitudes. Populations from higher altitudes constitutively produced less sesquiterpene lactones and did not suffer from suppression under low atmospheric pressure.

4. Synthesis. We conclude that atmospheric pressure modulates root growth and defence traits, and that evolutionary history shapes plant phenotypic responses to atmospheric pressure. Our findings have important implications for our understanding of altitudinal gradients and the future use of plants as a source of food and bioactive metabolites in extraterrestrial habitats.
\end{abstract}

\section{KEYWORDS}

adaptation, altitude gradient, atmospheric pressure, dandelion, defence, intraspecific variation, phenotypic plasticity, secondary metabolites

\section{1 | INTRODUCTION}

Plants successfully colonize a wide range of terrestrial habitats. Their capacity to survive under variable and challenging environmental conditions is a prerequisite for their contribution to biodiversity and sustainable agriculture in the face of climate change, and their potential use as a source of food and medicine in future extraterrestrial habitats (Jump \& Peñuelas, 2005; Wheeler, 2017). Atmospheric pressure plays a potentially important role in terrestrial and extraterrestrial environments, albeit for different reasons. On earth, climate change research often relies on altitudinal gradients to understand how plants and terrestrial ecosystems will be affected

Carla C. M. Arce and Zoe Bont share first authorship.

This is an open access article under the terms of the Creative Commons Attribution License, which permits use, distribution and reproduction in any medium, provided the original work is properly cited.

(c) 2021 The Authors. Journal of Ecology published by John Wiley \& Sons Ltd on behalf of British Ecological Society 
by future climates. Such studies typically assume that differences in climate at different altitudes account for changes in plant performance, and that effects of atmospheric pressure are negligible. In contrast, space plant biology has long been interested in understanding effects of atmospheric pressure on plants, as it would be more practical to maintain low pressure greenhouses in future moon or mars colonies (Corey et al., 1997; Iwabuchi \& Kurata, 2003; Richards et al., 2006). Thus, understanding the impact of atmospheric pressure on plants and the capacity of plants to withstand and adapt to different atmospheric pressures is of substantial interest for the present and future of humanity. Yet, to date, our understanding of how atmospheric pressure influences plants is not well-developed.

How are plants affected by low atmospheric pressure? One consequence of low atmospheric pressure at high altitudes is the decrease of partial pressures of $\mathrm{O}_{2}$ and $\mathrm{CO}_{2}$, which are essential substrates for respiration and photosynthesis (Xu et al., 2015; Zabalza et al., 2009). Changes in $\mathrm{O}_{2}$ and $\mathrm{CO}_{2}$ partial pressures have been linked to changes in plant physiology and growth (He et al., 2007; Kammer et al., 2015; Paul et al., 2004; Zhou et al., 2017). Effects are complex, since the decrease of the partial pressure of the at mospheric gases is accompanied by an increase in diffusion rates, which may compensate for the low ambient concentration of the essential gases (Terashima et al., 1995). Further, as the diffusion coefficient for water vapour is increased, transpiration increases (Smith \& Geller, 1979), which can impose water stress on plants growing under reduced atmospheric pressure (Iwabuchi \& Kurata, 2003; Paul et al., 2004; Richards et al., 2006).

Can plants exhibit phenotypic plasticity to cope with low atmospheric pressure? Several studies suggest that plants respond dynamically to reduced atmospheric pressure (He et al., 2003; Iwabuchi \& Kurata, 2003; Richards et al., 2006; Spanarkel \& Drew, 2002). In the mountain plant Arabis alpina, for instance, stomatal density increases and stomata aperture narrows at low atmospheric pressure (Kammer et al., 2015). This induced response likely benefits the plant, because at low partial pressures of atmospheric gases, a higher stomatal density may ensure optimal supply of $\mathrm{CO}_{2}$ for photosynthesis (Woodward \& Bazzaz, 1988; Xu et al., 2016), while a narrow aperture of the stomata can restrict water loss to counteract increased transpiration rate (Buckley, 2005). At a molecular level, it is assumed that low atmospheric pressure represents an environmental stress to which plants must respond with changes in their metabolic pathways in order to survive successfully (Ferl et al., 2002; Paul \& Ferl, 2006). Recent research has documented extensive changes in gene expression patterns in Arabidopsis thaliana when exposed to a low atmospheric pressure environment, including genes associated with hypoxia and water loss (Paul et al., 2004; Zhou et al., 2017).

Can plants adapt to low atmospheric pressure over evolutionary time? Vascular plants colonize habitats between 0 and 6,150 $\mathrm{m}$ above sea level corresponding to atmospheric pressures between 101 and $46 \mathrm{kPa}$ (Angel et al., 2016). Since atmospheric pressure influences plant performance, and many plant species occur along altitudinal gradients, local adaptation to atmospheric pressure can be expected (Kammer et al., 2015; Ward et al., 2000; Ward \& Strain, 1997). Using growth chambers simulating high- and low-altitude pressure conditions, Kammer et al., (2015) found that Arabis alpina adjusts stomatal density in response to low atmospheric pressure, while the low-altitude plant Arabidopsis thaliana does not. Evidence for genetic differences in the response of stomatal density to pressure conditions was also found within species. Woodward and Bazzaz (1988) showed that in the grass Nardus stricta, plants from higher altitudes developed greater declines in stomatal density at experimentally increased $\mathrm{CO}_{2}$ partial pressure than plants from lower altitudes. Apart from stomatal development, very little is known about evolutionary adaptations of plants to low atmospheric pressure.

Plant secondary or specialized metabolites play important roles in plant responses and adaptations to diverse environments and stress factors (Hartmann, 2007; Moore et al., 2014), including herbivores and pathogens (Bednarek \& Osbourn, 2009; Ehrlich \& Raven, 1964; Kessler \& Baldwin, 2001; Moles et al., 2013), abiotic stress (Arbona et al., 2013; Nakabayashi \& Saito, 2015; Ramakrishna \& Ravishankar, 2011), mutualists (Pichersky \& Gershenzon, 2002; Schliemann et al., 2008; Stevenson et al., 2017) and other plants (Baldwin et al., 2006; Semchenko et al., 2014). The production, transport and storage of specialized metabolites is assumed to be costly (Neilson et al., 2013), and plants therefore constantly fine-tune their chemical arsenal to the demands of their environment and internal condition through phenotypic plasticity (Metlen et al., 2009). Over evolutionary times, environmental conditions may act as selective forces on plant genotype selection and can shape genetically determined chemical profiles of plants (Agrawal et al., 2012; Cunningham et al., 1999; Kessler \& Kalske, 2018; Züst et al., 2012). With increasing altitude, mountain habitats impose different environmental demands on plants, including harsher abiotic conditions and a lower intensity of biotic interactions (Buckley et al., 2019; Midolo \& Wellstein, 2020; Rasmann et al., 2014). Several studies found evidence that the genetic variation of plant secondary metabolites is shaped by these environmental gradients (Bakhtiari et al., 2019; Bernal et al., 2013; Bont et al., 2020; Buckley et al., 2019; Moreira et al., 2018). However, the role of decreasing atmospheric pressure at increasing altitudes in shaping the evolution and expression of plant secondary metabolites is poorly understood. Levine et al. (2008) found that the glucosinolate content in the roots of radish was decreased under hypobaric, normoxic conditions. In lettuce, the concentration of phenolics, anthocyanins and carotenoids in the leaves was increased under hypobaric and hypoxic conditions $(\mathrm{He}$ et al., 2013). However, all these experiments were conducted in lowpressure chambers under conditions far beyond the natural range of plants. How a plant's evolutionary history shapes its response to ecologically realistic low-pressure environments is unknown.

Along environmental gradients, closely related asexual and sexual plant taxa often have different distribution patterns-a phenomenon called geographic parthenogenesis (Glesener \& Tilman, 1978). It is generally predicted that apomictic plants with asexual reproduction tend to have larger distribution ranges including higher latitudes and higher altitudes, and thus lower atmospheric pressure, than their sexual relatives (Bierzychudek, 1985; Cosendai et al., 2013; 
Kearney, 2005). Hypotheses to explain these environmental distribution patterns include different colonization abilities of sexual and asexual organisms as well as different capacities to co-evolve with other organisms (e.g. reviewed in Hörandl, 2006 and in Tilquin \& Kokko, 2016). Although many studies empirically support the predicted geographical parthenogenesis patterns, some taxa with asexual and sexual organisms show opposite or mixed trends in geographic distribution. For the common dandelion Taraxacum officinale agg. (Asteraceae), a species complex that largely consists of diploid sexuals and triploid asexuals (Verduijn et al., 2004), larger latitudinal distribution of triploids has been observed, with triploids colonizing more extreme environments in the north of Europe (Menken et al., 1995; Van Dijk et al., 2003; Verhoeven \& Biere, 2013). Surprisingly however, triploids are less frequent at higher altitudes than diploids, at least along certain transects (Bont et al., 2020; Calame \& Felber, 2000). The reason for this pattern is currently unclear. One possibility is that high-altitude environments impose selection pressures that are different from high-latitude environments. Therefore, one hypothesis to explain the lower success of triploids at high altitude is that they are constrained by low resistance to low atmospheric pressure.

Taraxacum officinale possesses a reservoir of secondary metabolites stored in specialized cells, so called laticifers, throughout almost all organs. The latex of T. officinale is most abundant in the taproot. The latex is characterized by three major classes of secondary metabolites: hydroxyphenylacetate inositol esters with either two or three side chains (di-PIEs and tri-PIEs), the sesquiterpene lactone taraxinic acid $\beta$-d-glucopyranosyl ester (TA-G), and triterpene acetates (TritAc) (Huber et al., 2015). Latex is mainly connotated with defensive functions against herbivores and pathogens (Konno, 2011), and our previous work on the bioactivity and ecological role of the latex metabolites of $T$. officinale confirms this hypothesis (Bont et al., 2017; Huber, Bont, et al., 2016; Huber, Epping, et al., 2016). TA-G in particular reduces the attractiveness of T. officinale to white grubs and thereby increases plant performance (Huber, Epping, et al., 2016). Interestingly, in our recent study on the latex metabolites of 63 natural T. officinale populations across Switzerland we found a strong association of the latex metabolites TA-G and di-PIEs with the climatic history of the natural populations, which may be suggestive of a role of latex secondary metabolites in abiotic stress tolerance (Bont et al., 2020). Inside the lacticifers, latex is maintained at positive pressure, which allows it to be expelled after tissue disruption. Latex likely responds to turgor pressure (Agrawal $\&$ Konno, 2009), which in turn is determined by the water balance of the plant. At low atmospheric pressure, evaporation is increased, which could therefore have a direct or indirect effect on latex quality or quantity.

Here, we took advantage of experimental stations in Switzerland between 526 and 3,450 m a.s.l. with standardized abiotic conditions to study the effects of atmospheric pressure on the growth and latex composition of T. officinale. We included offspring from nine natural populations from Switzerland from different altitudes, including populations containing both diploid and triploid cytotypes.
This setup allowed us to test (a) whether low atmospheric pressure affects plant growth and latex composition through environmental plasticity; (b) whether there are signatures of local adaptation to atmospheric pressure, with populations from higher altitudes performing better at low atmospheric pressure and (c) whether low atmospheric pressure has a stronger impact on triploid than diploid plants, thus potentially restricting the expansion of triploids towards higher altitudes.

\section{2 | MATERIALS AND METHODS}

\subsection{Study species and seed collection}

The common dandelion is a latex-producing species complex with a world-wide, cosmopolitan distribution (Stewart-Wade et al., 2002). The wind-dispersed perennial herb can tolerate a broad range of environmental conditions and can be found from sea level to altitudes of up to 4,000 m a.s.l. (Molina-Montenegro et al., 2013; Sandoya et al., 2017). In Switzerland, the plant occurs at altitudes of up to 2,000 m a.s.I. (Calame \& Felber, 2000). In this study, plants from nine natural populations of Switzerland were included. The nine populations are a subset of 63 populations that were characterized in our previous work (Bont et al., 2020). They cover an altitudinal range from 302 to 1,607 m a.s.I (Figure 1a,b; Table S1). Each population was located within a maximal distance of $1 \mathrm{~km}$ from a meteorological monitoring station of MeteoSwiss, the Swiss Federal Office for Meteorology and Climatology, which enabled us to obtain long-term data on climatic conditions. According to Bont et al. (2020), 10 variables were selected from the MeteoSwiss database, representing average air pressure, temperature, precipitation and light conditions of the populations for the years 1996-2015. For most variables, data were available for all nine populations (Figure S1c). Seeds from the natural populations were collected and F2 plants were generated for each population as described in Bont et al. (2020). The cytotype distribution of each population was determined by analysing the ploidy level of the plants with flow cytometry (Bont et al., 2020). The nine F2 populations consisted of populations with only diploid plants (five populations) and populations with both triploid and diploid plants (four populations; Table S1).

\section{2 | Experimental design}

In order to investigate the effect of atmospheric pressure on the growth and chemical defence of T. officinale, we cultivated the F2 plants from the nine natural populations in four experimental stations at $526 \mathrm{~m}$ a.s.I. (Bern), 1,046 $\mathrm{m}$ a.s.l. (Adlemsried), 2,061 m a.s.l. (Kleine Scheidegg) and 3,450 m a.s.l. (Jungfraujoch) in Switzerland (Figure 1). Although T. officinale does not occur naturally in Switzerland at 3,450 $\mathrm{m}$ a.s.l. due to the cold climate, the plant is frequently reported at this altitude in the South American Andes (Sandoya et al., 2017) and is therefore not restricted in its occurrence 
(a)

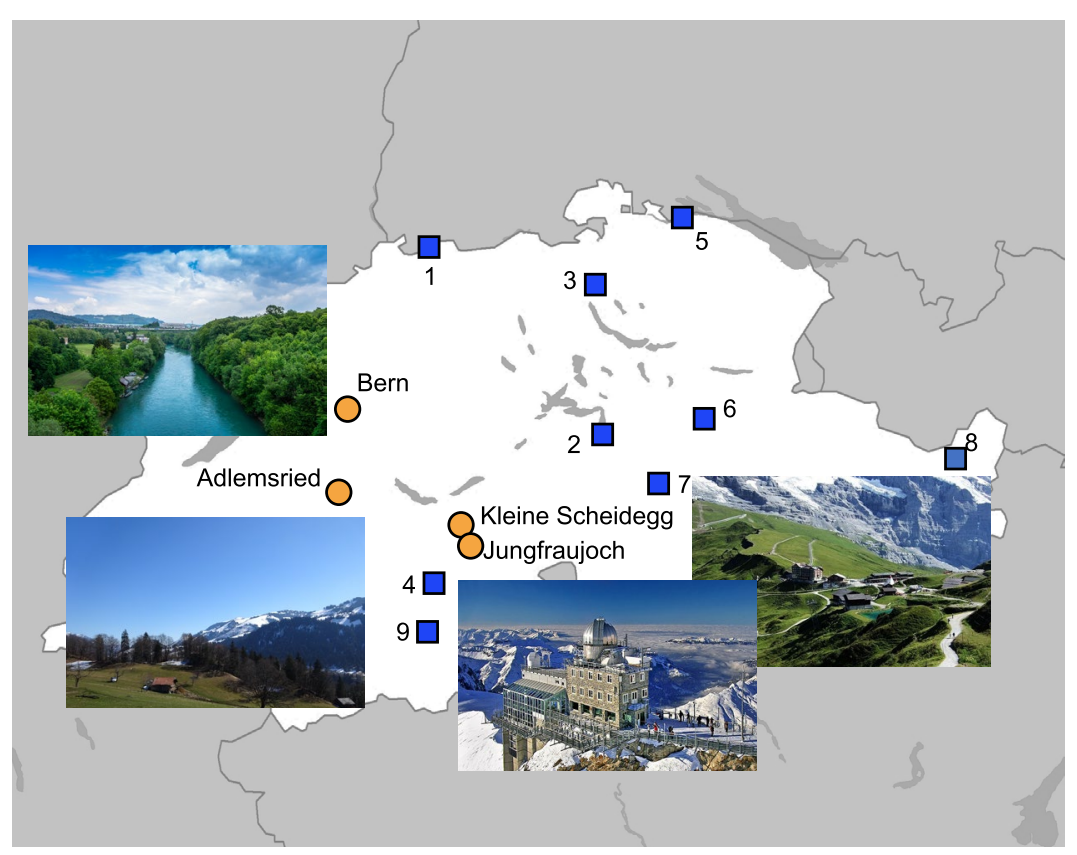

FIGURE 1 Geographical positions of the origins of the Taraxacum officinale populations (blue squares 1-9) and of the experimental stations (orange circles).

(a) Spatial distribution of the sites across Switzerland. (c) Photographs: Bern, CCO public domain; Adlemsried, Zoe Bont; Jungfraujoch, Julius Silver, CC BY-SA 4.0; Kleine Scheidegg, Grindel1, CC BY-SA 3.0. (b) Altitude and atmospheric pressure of the sites and representation of the linear relationship between these two parameters. (c) Visualization of plant growth conditions at experimental stations, including controlled abiotic parameters (grey bars) and varying atmospheric pressure (orange bars). Temperature and relative humidity: mean $\pm S D$ (measurement every hour) (b)

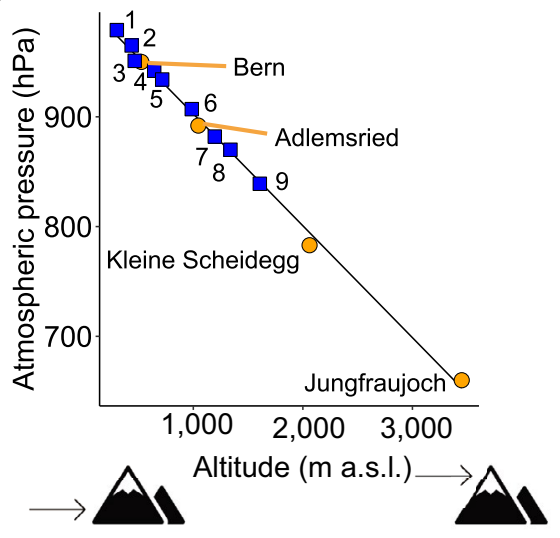

Population origins

O Experimental sites (c) Atmospheric pressure $(\mathrm{hPa})$

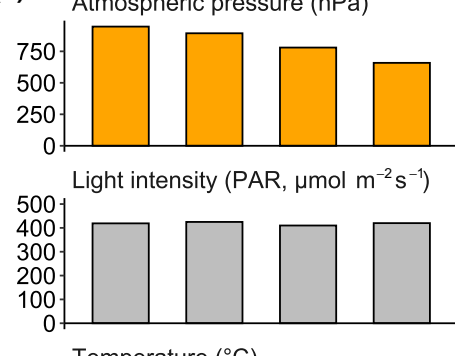

Temperature $\left({ }^{\circ} \mathrm{C}\right)$

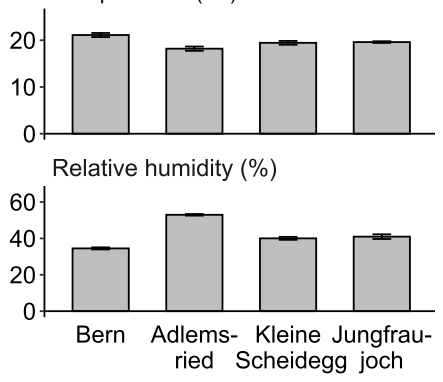

Experimental sites by the associated low atmospheric pressure. In the experimental stations, the plants were grown inside under controlled light supply, temperature and relative humidity and ambient indoor air quality. This allowed us to specifically test the influence of the atmospheric pressure gradient, ranging from 950 to $660 \mathrm{hPa}$ (Figure 1c).

For experiments, seeds from 6 to 8 mother plants (F1) per population were germinated on moist seedling substrate and transplanted into individual 1 l pots filled with potting soil ( 5 parts field soil, 4 parts peat, 1 part sand) after $18 \pm 2$ days. All plants were grown under controlled conditions $\left(25 \pm 2^{\circ} \mathrm{C}, 60 \pm 5 \% \mathrm{RH}, 16: 8\right.$ light:dark cycle) in Bern. $24 \mathrm{hr}$ after transplantation, the plants were distributed among the four experimental stations, so that 6-8 plants from each of the nine populations were cultivated in each station. The atmospheric pressure at the experimental stations was measured at the beginning of the experiment and 2 weeks later. With $0.3 \%-0.8 \%$ difference between the two measurements, the variation was negligible, and we thus used atmospheric pressure as a constant environmental factor in the experiment. The temperature and relative humidity were measured hourly at all stations with RHT10-Data Logger (Extech Instruments, China). To standardize light supply, we grew the plants in rooms with reduced natural light and supplied them with LED lights (400 LED beads, LED type SMD 5730, $400 \pm 20 \mu \mathrm{mol} \mathrm{m}^{-2} \mathrm{~s}^{-1}$ ) placed 1 meter above the plants. The plants were watered three times a week and fertilized once a week. 


\section{3 | Assessment of plant traits and chemical analysis}

After 45 days of growth in the experimental stations, we transported the plants back to Bern to analyse growth and defence traits. To assess vegetative growth, we quantified the plant biomass by measuring the dry weight of roots and shoots separately and then calculated root:shoot ratios. To study defence traits, we measured the amount of taproot latex and quantified the concentration of the latex secondary metabolites TA-G, di-PIEs and tri-PIEs.

To quantify latex traits, plants were cut $0.5 \mathrm{~cm}$ below the tiller and the taproot latex that was released over $20 \mathrm{~s}$ was collected and weighted. Two microlitres of latex was immediately transferred into $200 \mu \mathrm{l}$ methanol for chemical analysis. The roots were carefully washed with tap water and roots and shoots were placed in a drying oven at $50^{\circ} \mathrm{C}$ until constant dry mass was reached. The chemical analysis of the latex metabolites was carried out as described in Bont et al. (2017). Briefly, the samples were vortexed for $10 \mathrm{~min}$, ultrasonicated for $10 \mathrm{~min}$, centrifuged at $4^{\circ} \mathrm{C}$ and $14,000 \mathrm{rpm}$ for $20 \mathrm{~min}$ and supernatants were used for further analysis. Relative concentrations of TA-G, di-PIEs and tri-PIEs were determined by injecting the latex extracts into an Acquity UPLCPDA-MS (Waters) with electrospray ionization in positive mode, consisting of an ultra-performance liquid chromatograph (UPLC) coupled to a photodiode array detector (PDA) and a single quadrupole mass detector (QDa). For quantification, peak areas were integrated at $245 \mathrm{~nm}$ for TA-G and at $275 \mathrm{~nm}$ for di- and tri-PIES, while concurrently recorded characteristic mass features were used to confirm compound identities (Bont et al., 2017). For absolute quantification of TA-G, we established an external standard curve with loganin (CAS: 18524-94-2, Sigma-Aldrich Chemie GmbH) and calculated the corresponding response factor to pure TA-G. (Bont et al., 2017). For di-and tri-PIEs, relative concentrations were calculated separately.

\subsection{Statistical analysis}

All statistical analyses were performed in $R$ 4.0.2 ( $R$ Core Team, 2017). To represent the climatic conditions associated with the different altitudes of the populations we first conducted a principal component analysis (PCA), as some of the meteorological variables of the population origins were highly correlated (Figure S1c). This approach is widely used to analyse the impact of climate on the evolution of plant traits (Keller et al., 2009; Kooyers et al., 2015; Villaverde et al., 2017). We applied the function 'prcomp' on scaled variables to reduce dimensionality of the data and selected the axis that explained most of the cumulative variance and represented the climatic conditions associated with the different altitudes at which the populations evolved (climPCA1).

For data exploration, we calculated a correlation matrix of all parameters included in the experiment. Then, we analysed all data with linear mixed-effects models (LMEMs; Bates, 2020). The models were fit using the function 'Imer' from the package 'LME4'
(Bates et al., 2015) with restricted maximum likelihood estimation (REML). Variables representing fixed effects were scaled and centred prior to computation to reduce nonessential multicollinearity (lacobucci et al., 2016). If necessary, log-transformation was applied to the response variable to improve distribution of variance. Model assumptions were validated using 'plotresid' from the package 'RVAideMemoire' (Hervé, 2018). The significances of the fixed effects were estimated using the package 'LMERTEST' (Kuznetsova et al., 2017) by calculating type II analysis of variance tables with Kenward-Rodger's approximation to degrees of freedom (Halekoh \& Højsgaard, 2014).

To test the overall effect of the varying atmospheric pressure of the experimental stations on plant growth and defence, we performed LMEMs separately for each plant trait (root dry weight, shoot dry weight, root:shoot ratio, taproot latex, TA-G, di-PIEs, tri-PIEs). We used the mean value per trait per population per station as response variable, tested the fixed effect of the atmospheric pressure of the experimental station (' $P_{\text {Station }}$ ') and included '(1|Population)' as random effect and grouping factor to allow for varying intercepts between populations. We performed a similar analysis to assess the overall effect of the climatic conditions associated with the different altitudes of the population origins on plant growth and defence by testing the fixed effect of 'climPCA1' and including '(1|Station)' as random effect and grouping factor to allow for varying intercepts between experimental stations. To visualize the significant effects, linear regression analyses were performed, and adjusted $R^{2}$-values were calculated.

In order to further investigate interacting effects of the climatic conditions associated with different altitudes of the population origins (genetic effects) and the atmospheric pressure of the experimental stations (environmental effects) on the plants, we next conducted a full model analysis for each plant trait, including the abiotic environment of the stations as covariate. Since temperature and relative humidity were highly correlated (Pearson's $r=-0.95$, Figure S3), we used only temperature as covariate in the model. Trait values of individual plants were used as response variables, with '(1|Population)' as random effect to allow the calculation of separate intercepts for each population. Concurrently, the impact of ploidy was tested by adding the ploidy level (diploid or triploid) of each plant as fixed effect. The full model syntax was the following: plant trait $\sim \operatorname{climPCA} 1 \times \mathrm{P}_{\text {Station }}+\mathrm{P}_{\text {Station }} \times$ temperature $+\mathrm{P}_{\text {Station }} \times$ Ploidy $+(1 \mid$ Population). As expected, temperature influenced all experimental parameters (LMEMs: Temp, $p<0.05$, Table 1), but did not interact with atmospheric pressure (LMEMs: $\mathrm{P}_{\text {Station }} \times$ Temp, $p<0.05$, Table 1). A confounding effect of residual variation in temperature on the detected effects of atmospheric pressure is, therefore, unlikely. To visualize the significant interactive effect of 'climPCA1 $\times \mathrm{P}_{\text {Station }}$ ' on TA-G and on di-PIEs concentration, we then used the package 'EFFECTS' (Fox et al., 2019) for model prediction with unscaled and uncentred fixed effects, excluding the non-significant interaction of ' $P_{\text {Station }} \times$ temperature' from the model. Likewise, we predicted and visualized the nonsignificant effects of $\mathrm{P}_{\text {Station }} \times$ Ploidy on all measured plant traits. All results 
TAB LE 1 Effects of experimental atmospheric pressure $\left(P_{\text {Station }}\right)$, of climatic conditions associated with different altitudes of population origins (climPCA1), of the plant's ploidy level (Ploidy) and of selected interactions on performance and latex profile of Taraxacum officinale are shown. Temperature of experimental station (Temp) is included as control variable. Results of full mixed-effects model analyses are displayed separately for each performance parameter (root dry weight, shoot dry weight, root:shoot ratio, amount of latex) and for each class of latex secondary metabolites. Significances of fixed effects were assessed by $F$ tests. Estimated $F$-values (NumDF, DenDF) ${ }^{\text {are shown. }}$ Levels of statistical significance are indicated with asterisks $\left({ }^{* * *} p<0.001 ;{ }^{* *} p<0.01 ;{ }^{*} p<0.05 ;\left({ }^{*}\right) p<0.1\right)$

\begin{tabular}{|c|c|c|c|c|c|c|c|}
\hline & Root & Shoot & Root:shoot & Latex & TA-G & di-PIEs & tri-PIEs ${ }^{a}$ \\
\hline Temp & $\begin{array}{l}6.26_{(1,210)} \\
*\end{array}$ & $\begin{array}{l}4.16_{(1,210)} \\
*\end{array}$ & $1.62_{(1,209)}$ & ${ }_{* * *}^{11.41_{(1,210)}}$ & $\begin{array}{l}4.17 \\
*\end{array}$ & ${ }_{* *}^{8.03_{(1,211)}}$ & ${ }_{* *}^{8.21_{(1,211)}}$ \\
\hline climPCA1 $\times \mathrm{P}_{\text {station }}$ & $0.72_{(1,209)}$ & $2.47_{(1,209)}$ & $0.40_{(1,209)}$ & $0.08_{(1,209)}$ & ${ }_{* *}^{7.26_{(1,211)}}$ & $\begin{array}{c}6.49_{(1,211)} \\
*\end{array}$ & $2.06_{(1,211)}$ \\
\hline$P_{\text {station }} \times$ Temp & $0.49_{(1,210)}$ & $0.13_{(1,210)}$ & $1.33_{(1,210)}$ & $\begin{array}{l}3.32_{(1,210)} \\
\left({ }^{*}\right)\end{array}$ & $0.27_{(1,212)}$ & $0.00_{(1,212)}$ & $0.09_{(1,211)}$ \\
\hline $\mathrm{P}_{\text {station }} \times$ Ploidy & $0.67_{(1,209)}$ & $1.75_{(1,209)}$ & $1.08_{(1,209)}$ & $0.50_{(1,209)}$ & $0.91_{(1,211)}$ & $0.48_{(1,211)}$ & $3.30_{(1,211)}$ \\
\hline
\end{tabular}

Abbreviations: di-PIEs, di-4-hydroxyphenylacetate inositol esters; TA-G, taraxinic acid ß-D-glucopyranosyl ester; tri-PIEs, tri-4-hydroxyphenylacetate inositol esters.

${ }^{a} \log$-transformed.

were visualized using 'ggplot2' (Wickham, 2016) and 'effects' (Fox et al., 2019).

\section{3 | RESULTS}

\section{1 | Validation of experimental setup}

We first tested whether our efforts to standardize environmental parameters across experimental sites were successful. We found that indoor temperature and relative humidity varied slightly between sites (Figure 1c), but neither variable was correlated to atmospheric pressure (Figure S3). As plants were also grown using identical potting soil, watering, lighting and comparable indoor environments with respect to air pollution, we estimate that major abiotic parameters were successfully standardized to allow for an assessment of the role of atmospheric pressure on $T$. officinale (see discussion for a critical assessment of this aspect). By growing T. officinale plants from seeds of diploid and triploid populations originating from different altitudes, we tested (a) the effect of atmospheric pressure on growth and defence; (b) the impact of population origin on plant responses to atmospheric pressure (as an indicator for local adaptation to atmospheric pressure) and (c) the importance of a plant's cytotype (diploid vs. triploid) on its capacity to grow under different atmospheric pressure, as a test of the hypothesis that low atmospheric pressure restricts the establishment of triploids at high altitudes. To this end, we first describe environmental (Figure 2) and heritable contributions (Figure 3) to variation in defence and growth independently. Using a full model, we then address adaptive phenotypic plasticity (Table 1; Figure 4) and differences between cytotypes (Table 1; Figure 5).

\subsection{Atmospheric pressure modulates root growth and defences}

Across all populations and irrespective of population origin and cytotype, T. officinale plants showed distinct phenotypes as a function of atmospheric pressure at the different experimental sites (Figure 2). Both root growth and root:shoot ratio were overall lower at higher altitudes with lower atmospheric pressure (LMEM, $p=0.022$, Figure 2 resp. LMEM, $p<0.001$, Figure 2). By contrast, no significant effects on shoot growth and on the amount of exuded taproot latex were observed (LMEMs, $p>0.05$, Figure 2). The concentration of the defence metabolite TA-G in the taproot latex was reduced in plants growing under lower atmospheric pressure (LMEM, $p=0.001$, Figure 2). The concentrations of di-PIEs and tri-PIEs did not vary significantly with atmospheric pressure (LMEMs, $p>0.05$, Figure 2). Thus, growth under low atmospheric pressure is specifically associated with lower root growth and lower accumulation of a defensive sesquiterpene lactone in T. officinale.

\section{3 | Climatic history associated with altitude shapes heritable variation in root defences}

To characterize the climatic conditions under which the T. officinale populations evolved, we conducted a principal component analysis 
FIGURE 2 Overall effect of atmospheric pressure of experimental station on mean plant performance parameters (root dry weight, shoot dry weight, root:shoot ratio, taproot latex) and chemical composition of latex (TA-G, di-PIEs, tri-PIEs). Blue dots represent average values across all populations per experimental station, while black dots represent average values per population per experimental station ( $N=5-8$ per population and station). The significance of the effect was tested with linear mixed-effects models (LMEM) and corresponding $p$-values are displayed. For statistically significant effects $(p<0.05)$ linear regression lines in blue and $R^{2}$-values of the linear regressions (LR) are shown. Linear regressions are shown for illustrative purposes and do not represent the full complexity of the statistical models used to determine significant effects. TA-G: taraxinic acid ß-D-glucopyranosyl ester; di-PIEs: di-4hydroxyphenylacetate inositol esters; triPIEs: tri-4-hydroxyphenylacetate inositol esters

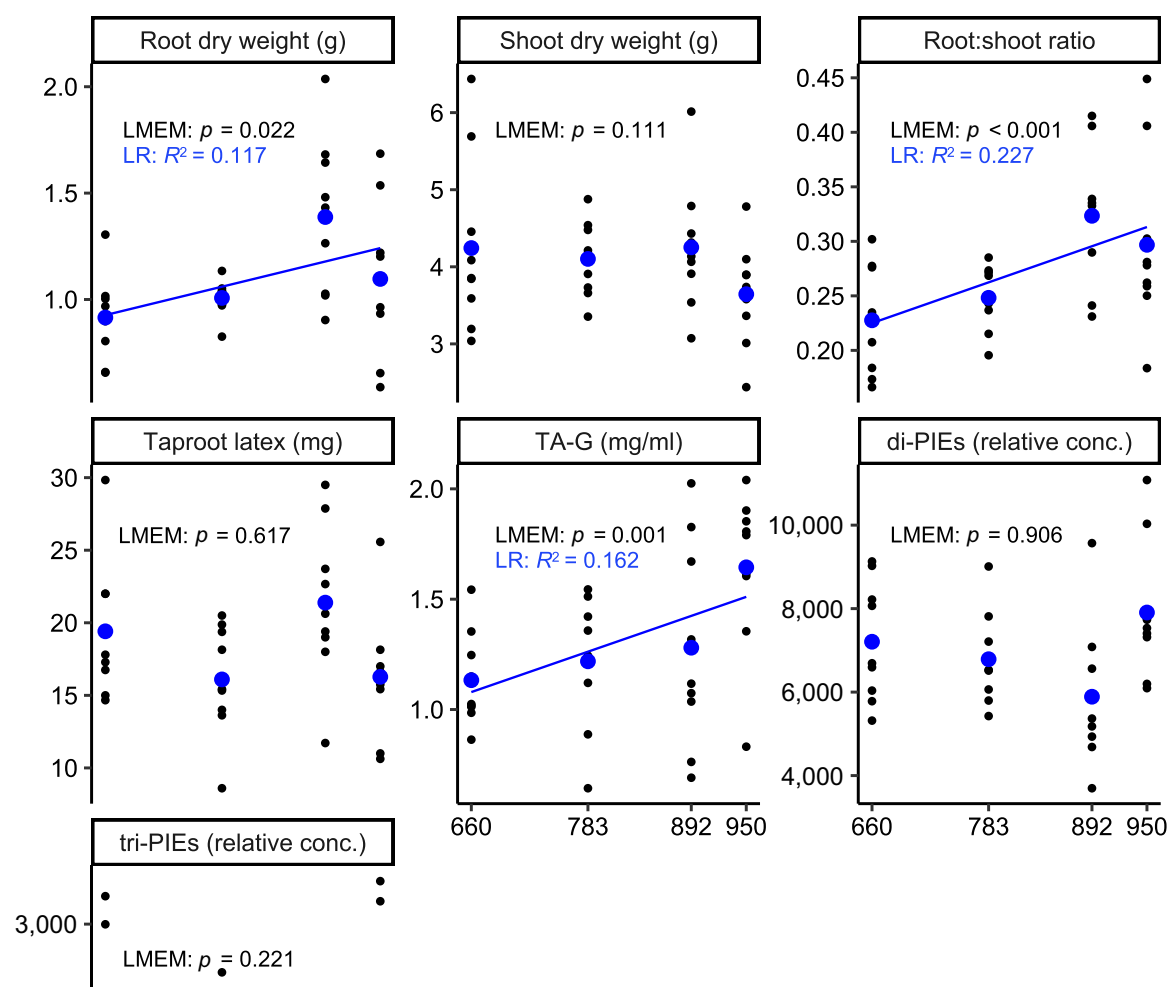

- Average value per population per experimental station

- Average value across all populations per experimental station
(PCA) and then scaled variables to reduce the dimensionality of the data. The first two axes (climPCA1 and climPCA2) together explained $90 \%$ of the cumulative variance in climate parameters (Figure S1a). $54.3 \%$ of the variance was explained by the first axis (climPCA1) which mainly represents variation in temperature-related parameters and atmospheric pressure (Figure S1a,c). ClimPCA1, but not climPCA2 was highly correlated with the altitude of the population origin (Pearson's $r=0.941, p<0.001$, Figure S1b). We therefore used climPCA1 to represent the climatic conditions associated with the different altitudes of the populations.

Across experimental stations, we found no significant association between climPCA1 and T. officinale growth (LMEMs, $p>0.05$, Figure 3). However, climPCA1 was correlated to the amount of taproot latex and the concentration of TA-G, with populations originating from lower altitudes producing more latex and more TA-G than populations collected at high altitudes (LMEMs, $p<0.001$, Figure 3). No clear effects were observed for di- and tri-PIEs (LMEMs, $p>0.05$, Figure 3). Thus, climatic conditions that are correlated with altitude are associated with heritable differences in the production and chemical composition of root latex, with plant originating from higher altitudes producing less latex and defensive sesquiterpene lactones.

\subsection{Root defences show patterns of adaptation to high atmospheric pressure}

In a next step, we constructed a full model to detect interactions between the climatic history of the populations (climPCA1) and the atmospheric pressure of the experimental sites at which the plants were grown $\left(P_{\text {Station }}\right)$. The full model confirmed that the concentration of TA-G in the latex is influenced by climPCA1 (LMEM: climPCA1, $p=0.017$, Table 1 , Figure 3), and that atmospheric pressure at the experimental sites is associated with changes in root growth (LMEM: $\mathrm{P}_{\text {Station }}, p=0.001$, Table 1 , Figure 2), root:shoot ratio (LMEM: $\mathrm{P}_{\text {Station }}, p<0.001$, Table 1, Figure 2) and TA-G concentration in root latex (LMEM: $\mathrm{P}_{\text {Station }}, p<0.001$, Table 1 , Figure 2). In addition, we detected a negative effect of atmospheric pressure on the concentration of tri-PIEs (LMEM: $\mathrm{P}_{\text {Station }}, p=0.019$, Table 1, Figure 2). We detected no significant interactions between the climatic history of the populations (climPCA1) and atmospheric pressure at the experimental sites for root or shoot growth (LMEM: climPCA1 $\times \mathrm{P}_{\text {Station, }}$, $p=0.05$, Table 1). However, a significant interaction was observed for TA-G concentration (LMEM: climPCA1 $\times \mathrm{P}_{\text {Station }}, p=0.008$, Table 1), indicating natural selection for phenotypic variability of TA-G production under different atmospheric pressure. Closer inspection of the data 


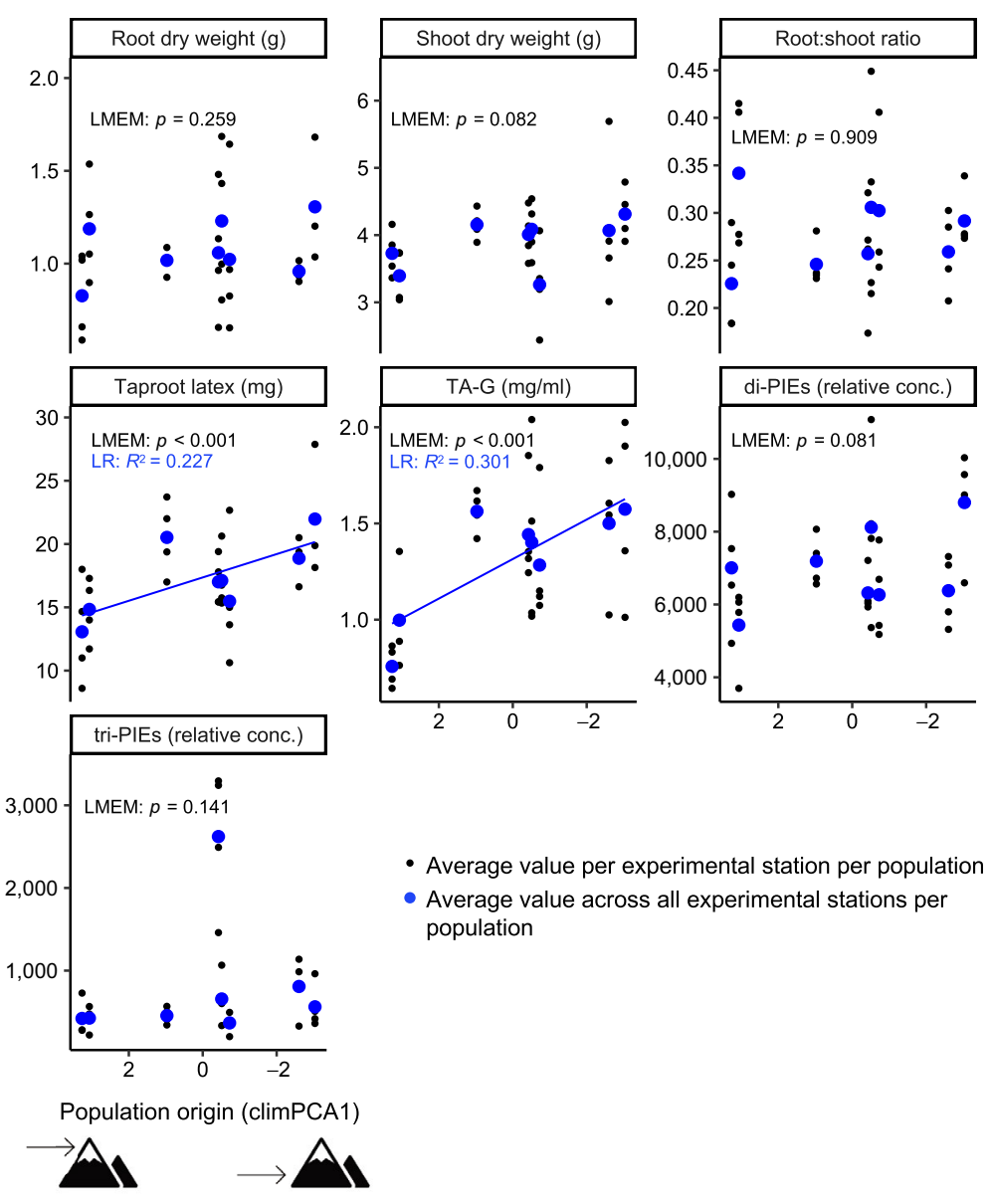

FIGURE 3 Overall effect of climatic conditions associated with different altitudes of population origins (climPCA1) on mean plant performance parameters (root dry weight, shoot dry weight, root:shoot ratio, taproot latex) and chemical composition of latex (TA-G, di-PIEs, tri-PIEs). climPCA1 represents a climatic gradient ranging from high-altitude environment to low-altitude environment, which is illustrated by icons. Blue dots represent average values per population across all experimental stations, while black dots represent average values per population per experimental station ( $N=5-8$ per population and station). The significance of the effect was tested with linear mixed-effects models (LMEM) and corresponding $p$-values are displayed. For statistically significant effects $(p<0.05)$ linear regression lines in blue and $R^{2}$-values of the linear regressions (LR) are shown. Linear regressions are shown for illustrative purposes and do not represent the full complexity of the statistical models used to determine significant effects. TA-G: taraxinic acid ß-D-glucopyranosyl ester; di-PIEs: di4-hydroxyphenylacetate inositol esters; tri-PIEs: tri-4-hydroxyphenylacetate inositol esters

revealed that TA-G concentrations in populations originating from lowaltitude environments were more strongly influenced by atmospheric pressure than in populations from high-altitude environments (Figure 4a). Under high atmospheric pressure, populations from low-altitude environments produced significantly more TA-G than populations from high-altitude environments (Figure 4a). With decreasing atmospheric pressure, this difference disappeared, leading to similar TA-G concentrations at $660 \mathrm{hPa}$. A similar pattern, albeit with more variability, was observed for di-PIEs (LMEM: climPCA1 $\times \mathrm{P}_{\text {Station, }}, p=0.012$, Table 1 , Figure $4 \mathrm{~b}$ ). These results are suggestive of adaptation of root defence expression of low-altitude populations to high atmospheric pressure.

\subsection{The performance of triploid plants is not constrained by resistance to atmospheric pressure}

To test whether plant cytotype influences the capacity of $T$. officinale to grow at different atmospheric pressures, we tested for interactions between cytotype and atmospheric pressure at the different experimental sites. Across experimental sites, we did not detect any significant differences between diploid and triploid plants for any of the measured parameters (LMEMs: Ploidy, $p>0.05$, Table 1, Figure 5). We also found no significant interactions between cytotype and atmospheric pressure (LMEMs: 
FIGURE 4 Visualization of the significant interaction effect of the climatic conditions associated with different altitudes of the population origins (climPCA1) on TA-G concentration (a) and on concentration of di-PIEs (b) in the latex depending on the atmospheric pressure of the experimental station. Blue lines indicate predicted slopes from the mixed-effects model, with 95\% confidence interval shaded. TA-G: taraxinic acid ß-D-glucopyranosyl ester; di-PIEs: di-4-hydroxyphenylacetate inositol ester

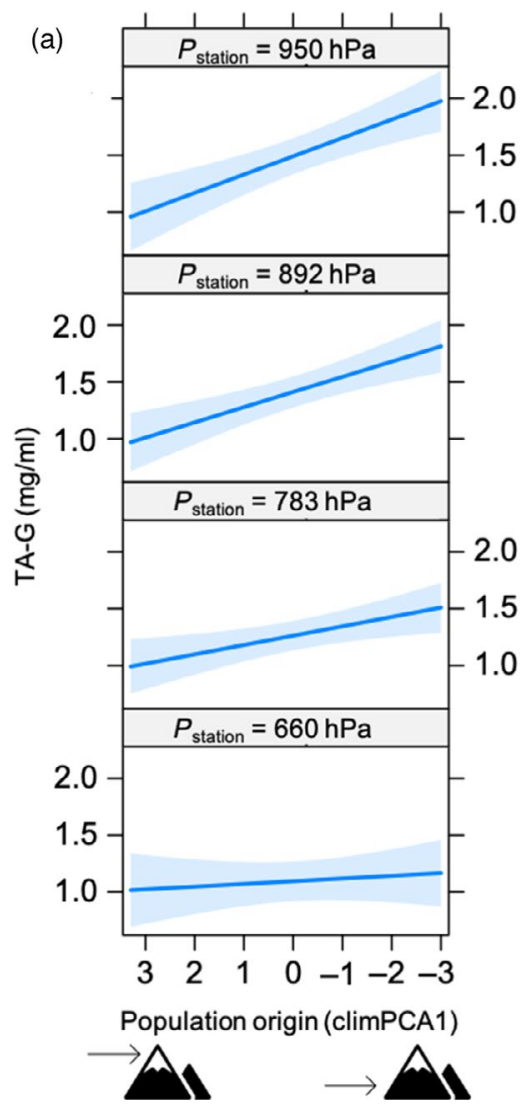

$\mathrm{P}_{\text {Station }} \times$ Ploidy, $p>0.05$, Table 1, Figure 5). Thus, the hypothesis that low atmospheric pressure restricts the performance of triploids at high altitudes is not supported by our data.

\section{4 | DISCUSSION}

Plants can adjust to the demands of changing environmental conditions through genetic differentiation and environmental plasticity. Whether and how atmospheric pressure as an environmental factor shapes plant ecology and evolution is poorly understood. By growing several T. officinale populations in controlled environments, our study provides evidence that atmospheric pressure influences plant root growth and chemical defence irrespective of the cytotype level of the plants and shows that the natural habitats of the populations shape the potential for phenotypic variability in response to varying atmospheric pressure. Here, we discuss our findings in an eco-evolutionary and plant-physiological context.

\subsection{Impact of reduced atmospheric pressure on plant biomass}

Although many plants seem to be capable to grow vegetatively at pressures even below $25 \mathrm{kPa}$ (Richards et al., 2006), they suffer from stress associated with hypoxia and desiccation and in turn develop responses and adaptations, which are often organ-specific
(Zhou et al., 2017). In environments with reduced $\mathrm{O}_{2}$ and $\mathrm{CO}_{2}$ availability, roots may react more strongly to oxygen deficiency because, as heterotrophic organs, they are highly dependent on oxygen for mitochondrial energy production, while shoots, as autotrophic plant organs, may be restricted in photosynthesis due to the reduced $\mathrm{CO}_{2}$ diffusion rate (Mustroph et al., 2014). Our results show that root but not shoot growth of $T$. officinale is reduced in low atmospheric pressure environments, resulting in a decrease of the root:shoot ratio. In our experimental stations, the reduction in atmospheric pressure is associated with naturally decreased levels of atmospheric gases including a reduced partial pressure of $\mathrm{O}_{2}$, and we assume that the resulting mild hypoxia restricts root growth of $T$. officinale. This finding is in line with previous studies showing that roots are particularly sensitive to reduced $\mathrm{O}_{2}$ partial pressure (He et al., 2007; Tang et al., 2015), whereas several studies with plants cultivated at reduced atmospheric pressure, but with a partial pressure of $\mathrm{O}_{2}$ experimentally maintained at the same level as at ambient pressure, found no reduction in root biomass (Iwabuchi et al., 1996; Levine et al., 2008; Spanarkel \& Drew, 2002).

\subsection{Impact of reduced atmospheric pressure on the sesquiterpene lactone TA-G}

Exposure to low atmospheric pressure also affects plant chemistry $(\mathrm{He}$ et al., 2013; Levine et al., 2008; Zhou et al., 2017). In our study we 

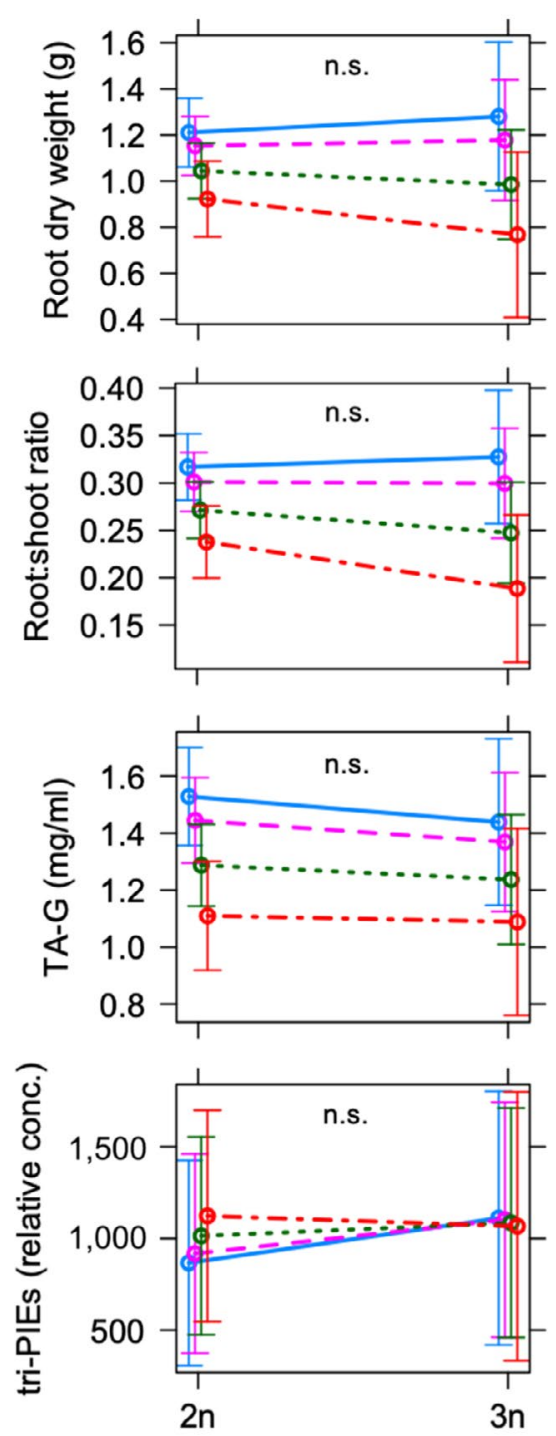

Ploidy
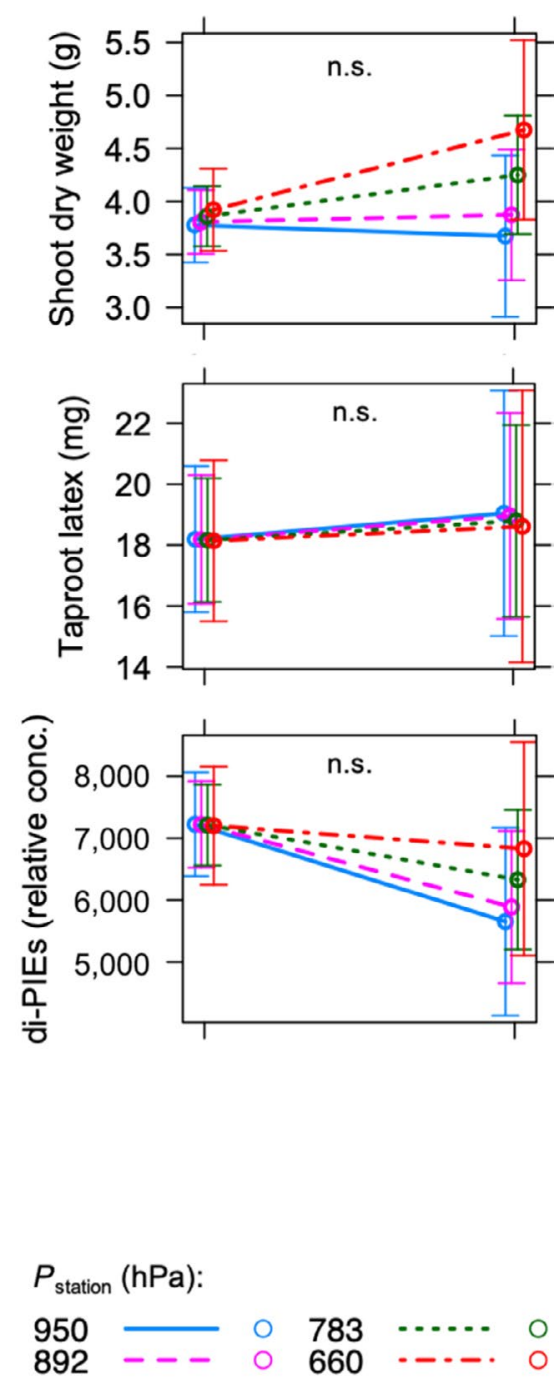

FIGURE 5 Visualization of influence of ploidy on plant parameters depending on atmospheric pressure of experimental station. Predicted mean values with standard errors from mixed-effects models are shown. None of the plant parameters differ statistically significantly between diploid and triploid plants (n.s.: $p>0.05)$. 2n: diploid; 3n: triploid; TA-G: taraxinic acid $ß$-D-glucopyranosyl ester; di-PIEs: di-4-hydroxyphenylacetate inositol esters; tri-PIEs: tri-4hydroxyphenylacetate inositol esters detected a decline in the concentration of the secondary metabolite TA-G in the latex of T. officinale with decreasing atmospheric pressure. TA-G is constitutively produced by the plant, acts repellent against root feeders and therefore defends the plant against herbivores (Bont et al., 2017; Huber, Epping, et al., 2016). To reduce the costs associated with constitutively produced chemical defences (Neilson et al., 2013), plants may use abiotic conditions as external stimuli to adjust the level of defensive secondary metabolites to the expected herbivore pressure. Temperature, for instance, is assumed to be a good indicator for herbivore attack in the field, because herbivore appearance and activity is often modulated by temperature (Bale et al., 2002). In our previous work, we found evidence that $T$. officinale can use seasonal temperature variation to synchronize deployment of chemical defences with expected herbivore attack intensity in the field, indicating an important role of abiotic conditions in fine-tuning the level of constitutively produced defensive metabolites (Huang et al., 2019). With increasing altitude, it is often assumed that herbivore pressure decreases (Moreira et al., 2018). T. officinale might thus use low atmospheric pressure as an indicator of high-altitude growth conditions and associated expected lower herbivore pressure, and the observed decrease in TA-G production might be a fine-tuning of defence deployment to reduce costs and maximize plant fitness. The seeds of $T$. officinale are characterized by excellent flight abilities (Cummins et al., 2018) and occasionally disperse over distances of several kilometres using wind and convective updrafts (Tackenberg et al., 2003). Hence, along altitudinal gradients, T. officinale is expected to regularly colonize novel territories with different environmental requirements, which could promote the evolution of adaptive plastic responses that use atmospheric pressure as an abiotic signalling factor for local conditions, as suggested. However, these are highly speculative conclusions and require further investigations.

Our previous work has not only shown that TA-G is involved in herbivore defence in T. officinale, but it has also shown an association of TA-G with the climatic history of the plants' natural habitats, suggesting an additional role of TA-G in abiotic stress management (Bont et al., 2020). The climatic parameters associated with TA-G production included sun 
and rain intensity and were related to the latitude but not to the altitude of the natural populations-plants from the rainier North of Switzerland produced more TA-G than plants from the sun-intense regions in the South of Switzerland (Bont et al., 2020), leading to the hypothesis that TA-G may passively or actively be involved in moisture regulation. At low atmospheric pressure, water evaporation is increased, and evidence exists that when plants are grown under such conditions, their perceptual mechanisms of water movement are altered even when the plants are fully hydrated and do not experience actual desiccation (Paul et al., 2004; Zhou et al., 2017). The decline in TA-G concentration with decreasing atmospheric pressure observed in our study could therefore be a direct or indirect consequence of increased evapotranspiration and would then support an involvement of TA-G in moisture regulation.

\subsection{Heritable variation for plasticity in TA-G production indicates adaptive value}

The capacity of phenotypic plasticity allows a plant with a given genotype to adjust its phenotype to the demands of contrasting environments (Nicotra et al., 2010; Sultan, 2000). In our experiments, the employed atmospheric pressure gradient was associated with measurable phenotypic plasticity, which again emphasizes the importance of atmospheric pressure for plant growth and development (Paul \& Ferl, 2006). For the latex metabolites TA-G and di-PIEs, plastic responses differed among populations, indicating heritable within-species variation for plasticity in these traits, likely shaped by the climatic histories of the populations. In high atmospheric pressure environments, plants from low-altitude environments produced more of the metabolites than plants from highaltitude environments, whereas in low atmospheric pressure environments, the difference between the populations vanished. The capacity of low-altitude plants to increase production of TA-G and di-PIEs when grown under low-altitude atmospheric pressure could benefit these plants and may be an adaptive trait, as latex metabolites have defensive functions against root feeders (Bont et al., 2017; Huber, Bont, et al., 2016; Huber, Epping, et al., 2016) and herbivore pressure is often expected to increase with decreasing altitude (Moreira et al., 2018; Rasmann et al., 2014). These findings are consistent with previous studies showing that within species, constitutive defences often decrease with increasing altitude (Bakhtiari et al., 2019; Buckley et al., 2019; Meyer \& Carlson, 2001; Pellissier et al., 2014). Our results further suggest that climatic conditions characterizing low-altitude environments select for genotypes with high plasticity in latex metabolite production, although whether the observed plasticity is a passive or active plastic response (van Kleunen \& Fischer, 2005) and whether its expression increases plant fitness remain to be elucidated.

\subsection{Plant performance at reduced atmospheric pressure does not differ between cytotypes}

Along altitudinal transects, diploid sexual T. officinale predominate over triploid asexual individuals at higher altitudes (Calame \& Felber, 2000), while along latitudinal gradients, triploids predominate over diploids at higher latitudes (Van Dijk et al., 2003). In our study, we tested the hypothesis that the performance of triploids at high altitudes is restricted by low atmospheric pressure. However, we found no evidence for a disadvantage of triploids at low atmospheric pressure, as diploids and triploids did not differ in any of the measured plant traits at different atmospheric pressures. The measured plant traits, however, estimate early plant performance and exclude traits related to dispersal, colonization and survival because the plants in this study were harvested before seed production. Therefore, although at reduced atmospheric pressure diploids and triploids exhibit similar growth and defence traits, we cannot rule out the possibility that the cytotypes differ in other fitness-determining traits that are crucial for long-term establishment. Further experiments on these traits would complement our results and provide a more comprehensive assessment of the role of atmospheric pressure in the geographic parthenogenesis of $T$. officinale.

\subsection{Atmospheric pressure should be considered in studies involving altitudinal gradients}

Studies comparing different species have shown that plants growing in high-altitude environments have developed adaptations to cope with the challenges of these environments (Halbritter et al., 2018) and that some of these adaptations, for example changes in stomatal development, are directly related to atmospheric pressure (Kammer et al., 2015). Our study confirms that atmospheric pressure is an important abiotic factor that influences plastic responses in plant growth and development and shows that across T. officinale populations, exposure to varying atmospheric pressures evokes heritable responses in growth and defence traits-responses that are shaped by the climatic conditions of the natural habitats of the populations. Given the nonnegligible impact of atmospheric pressure on the expression and likely also on the evolution of plant traits, we suggest that atmospheric pressure should be included by default as an abiotic factor when studying plant variation along altitudinal gradients to prevent results from being obscured by possibly unrecognized effects of atmospheric pressure variation. This may be particularly important when altitudinal gradients are used to surrogate climate change (Carlyle et al., 2014; Frei et al., 2014; Michalet et al., 2014), since atmospheric pressure, unlike temperature or precipitation, is not expected to change under global warming.

\subsection{Experimental considerations and conclusions}

An underlying assumption of our work is that we successfully standardized or randomized environmental parameters other than atmospheric pressure across the different experimental stations, thus allowing us to infer effects of this factor. Indeed, our experiment allowed us to control and/or randomize all major abiotic and biotic environmental parameters, including soil structure and composition, water supply, humidity, temperature as well as light quality and quantity and air pollution. Although 
temperature and relative humidity differed slightly among experimental stations, we found no significant interaction with the effect of the atmospheric pressure on plant growth and defence and conclude that our results are not confounded by these abiotic variables. Pests and pathogens were not observed on our plants. Another factor that depends on altitude and covaries with atmospheric pressure is gravity. Gravity decreases with altitude, resulting in a delta of $0.01 \mathrm{~m} / \mathrm{s}^{2}$ between Bern and the Jungfraujoch. Whether such a small change in gravity has any measurable impact on plants is unknown. Plant gravitropism depends on sensing inclination rather than gravitational force (Chauvet et al., 2016), and effects of reduced gravitational force are typically only observed below $0.3 \mathrm{~g}$ (Kiss et al., 2019). Thus, we infer that the effects observed in our study are the result of changes in atmospheric pressure rather than other environmental factors. Further experiments with pressure chambers (Paul et al., 2004) could be used as a future approach to confirm the patterns observed in our study.

Our results emphasize that within species, plants from different populations respond differently to varying atmospheric pressure, especially in the production of secondary metabolites. For successful cultivation of plants in extraterrestrial habitats as food source, it therefore may be worthwhile to screen various populations of the species of interest under low atmospheric pressure to detect resistant populations with secondary metabolite profiles suitable for human nutrition.

\section{ACKNOWLEDGEMENTS}

We thank Marc Pfander for his support with statistical analysis. We are grateful to Andrea Bonini for his help with field and laboratory work and to the gardeners of the University of Bern for taking care of the plants. We thank Hildegard Hinni, Annerös Erb, André Hofer, Christoph Steiner, Joan Fischer and Martin Fischer for watering the plants during the experiments at the research stations in Adlemsried, Kleine Scheidegg and Jungfraujoch. We thank the Kleine Scheidegg station of the Swiss Federal Railways to provide the room to perform the experiment. We thank the International Foundation High Altitude Research Station Jungfraujoch and Gornergrat (HFSJG) for the opportunity and support to conduct experiments at the Jungfraujoch. Meteorological data were provided by MeteoSwiss, the Swiss Federal Office for Meteorology and Climatology. We are grateful to the associate editor Mizanur Rahman and an anonymous reviewer for constructive and helpful suggestions and comments. This study was supported by the Swiss National Science Foundation (Grant No. 153517), the Seventh Framework Programme for Research and Technological Development of the European Union (FP7 MC-CIG 629134) and the HFSJG.

\section{CONFLICTS OF INTEREST}

The authors have no conflict of interest to declare.

\section{AUTHORS' CONTRIBUTIONS}

M.E., Z.B. and C.C.M.A. designed the study; C.C.M.A., R.A.R.M. and Z.B. collected data; Z.B., C.C.M.A. and P.F.C. analysed and interpreted the data; Z.B. and M.E. wrote the first draft of the manuscript. All authors contributed to the final version of the manuscript.

\section{PEER REVIEW}

The peer review history for this article is available at https://publons .com/publon/10.1111/1365-2745.13736.

\section{DATA AVAILABILITY STATEMENT}

Data available from the Dryad Digital Repository https://doi. org/10.5061/dryad.ht76hdrg5 (Arce et al., 2021).

\section{ORCID}

Carla C. M. Arce (iD https://orcid.org/0000-0002-1713-6970

Zoe Bont iD https://orcid.org/0000-0001-7215-7902

Paulo F. Cristaldo (iD https://orcid.org/0000-0003-4939-0487

Matthias Erb iD https://orcid.org/0000-0002-4446-9834

\section{REFERENCES}

Agrawal, A. A., Hastings, A. P., Johnson, M. T. J., Maron, J. L., \& Salminen, J.-P. (2012). Insect herbivores drive real-time ecological and evolutionary change in plant populations. Science, 338, 113-116. https:// doi.org/10.1126/science.1225977

Agrawal, A. A., \& Konno, K. (2009). Latex: A model for understanding mechanisms, ecology, and evolution of plant defense against herbivory. Annual Review of Ecology, Evolution, and Systematics, 40, 311-331. https://doi.org/10.1146/annurev.ecolsys.110308.120307

Angel, R., Conrad, R., Dvorsky, M., Kopecky, M., Kotilínek, M., Hiiesalu, I., Schweingruber, F., \& Doležal, J. (2016). The root-associated microbial community of the world's highest growing vascular plants. Microbial Ecology, 72(2), 394-406. https://doi.org/10.1007/s0024 8-016-0779-8

Arbona, V., Manzi, M., de Ollas, C., \& Gómez-Cadenas, A. (2013). Metabolomics as a tool to investigate abiotic stress tolerance in plants. International Journal of Molecular Sciences, 14(3), 4885-4911. https://doi.org/10.3390/ijms14034885

Arce, C. C. M., Bont, Z., Machado, R. A. R., Christaldo, P. F., \& Erb, M. (2021). Data from: Adaptations and responses of the common dandelion to low atmospheric pressure in high altitude environments. Dryad Digital Repository, https://doi.org/10.5061/dryad.ht76hdrg5

Bakhtiari, M., Formenti, L., Caggì, V., Glauser, G., \& Rasmann, S. (2019). Variable effects on growth and defense traits for plant ecotypic differentiation and phenotypic plasticity along elevation gradients. Ecology and Evolution, 9(7), 3740-3755. https://doi.org/10.1002/ ece3.4999

Baldwin, I. T., Halitschke, R., Paschold, A., Von Dahl, C. C., \& Preston, C. A. (2006). Volatile signaling in plant-plant interactions: 'Talking trees' in the genomics era. Science, 311(5762), 812-815. https://doi. org/10.1126/science.1118446

Bale, J. S., Masters, G. J., Hodkinson, I. D., Awmack, C., Bezemer, T. M., Brown, V. K., Butterfield, J., Buse, A., Coulson, J. C., Farrar, J., Good, J. E. G., Harrington, R., Hartley, S., Jones, T. H., Lindroth, R. L., Press, M. C., Symrnioudis, I., Watt, A. D., \& Whittaker, J. B. (2002). Herbivory in global climate change research: Direct effects of rising temperature on insect herbivores. Global Change Biology, 8(1), 1-16. https://doi.org/10.1046/j.1365-2486.2002.00451.x

Bates, D. (2020). Ime4: Mixed-effects modeling with R.

Bates, D., Maechler, M., Bolker, B. M., \& Walker, S. (2015). Fitting linear mixed-effects models using Ime4. Journal of Statistical Software, 67, 1-48. https://doi.org/10.18637/jss.v067.i01

Bednarek, P., \& Osbourn, A. (2009). Plant-microbe interactions: Chemical diversity in plant defense. Science, 324, 746-748. https://doi. org/10.1126/science.1171661

Bernal, M., Llorens, L., Julkunen-Tiitto, R., Badosa, J., \& Verdaguer, D. (2013). Altitudinal and seasonal changes of phenolic compounds 
in Buxus sempervirens leaves and cuticles. Plant Physiology and Biochemistry, 70, 471-482. https://doi.org/10.1016/j. plaphy.2013.06.012

Bierzychudek, P. (1985). Patterns in plant parthenogenesis. Experientia, 41(10), 1255-1264. https://doi.org/10.1007/BF01952068

Bont, Z., Arce, C. C. M., Huber, M., Huang, W., Mestrot, A., Sturrock, C. J., \& Erb, M. (2017). A herbivore tag-and-trace system reveals contact- and density-dependent repellence of a root toxin. Journal of Chemical Ecology, 43(3), 295-306. https://doi.org/10.1007/s1088 6-017-0830-3

Bont, Z., Züst, T., Arce, C. C. M., Huber, M., \& Erb, M. (2020). Heritable variation in root secondary metabolites is associated with recent climate. Journal of Ecology, 108, 2611-2624. https://doi. org/10.1111/1365-2745.13441

Buckley, J., Widmer, A., Mescher, M. C., \& De Moraes, C. M. (2019). Variation in growth and defence traits among plant populations at different elevations: Implications for adaptation to climate change. Journal of Ecology, 107(5), 2478-2492. https://doi. org/10.1111/1365-2745.13171

Buckley,T.N.(2005).Thecontrolofstomatabywaterbalance.NewPhytologist, 168(2), 275-292. https://doi.org/10.1111/j.1469-8137.2005.01543.x

Calame, F., \& Felber, F. (2000). Distribution of diploid sexual and triploid apomictic dandelions (Taraxacum sect. Ruderalia) along two altitudinal gradients in Switzerland. Botanica Helvetica, 110(2), 109-114.

Carlyle, C. N., Fraser, L. H., \& Turkington, R. (2014). Response of grassland biomass production to simulated climate change and clipping along an elevation gradient. Oecologia, 174(3), 1065-1073. https:// doi.org/10.1007/s00442-013-2833-2

Chauvet, H., Pouliquen, O., Forterre, Y., Legué, V., \& Moulia, B. (2016). Inclination not force is sensed by plants during shoot gravitropism. Scientific Reports, 6, 1-8. https://doi.org/10.1038/srep35431

Corey, K. A., Barta, D. J., \& Henninger, D. L. (1997). Photosynthesis and respiration of a wheat stand at reduced atmospheric pressure and reduced oxygen. Advances in Space Research, 20(10), 1869-1877. https://doi.org/10.1016/S0273-1177(97)00854-5

Cosendai, A. C., Wagner, J., Ladinig, U., Rosche, C., \& Hörandl, E. (2013). Geographical parthenogenesis and population genetic structure in the alpine species Ranunculus kuepferi (Ranunculaceae). Heredity, 110(6), 560-569. https://doi.org/10.1038/hdy.2013.1

Cummins, C., Seale, M., Macente, A., Certini, D., Mastropaolo, E., Viola, I. M., \& Nakayama, N. (2018). A separated vortex ring underlies the flight of the dandelion. Nature, 562, 414-418. https://doi. org/10.1038/s41586-018-0604-2

Cunningham, S. A., Summerhayes, B., \& Westoby, M. (1999). Evolutionary divergences in leaf structure and chemistry, comparing rainfall and soil nutrient gradients. Ecology, 69(4), 569-588. https://doi. org/10.1890/0012-9615(1999)069[0569:EDILSA]2.0.CO;2

Ehrlich, P. R., \& Raven, P. H. (1964). Butterflies and plants: A study in coevolution. Evolution, 18(4), 586-608. https://doi.org/10.1111/ j.1558-5646.1964.tb01674.x

Ferl, R. J., Schuerger, A. C., Paul, A.-L., Gurley, W. B., Corey, K., \& Bucklin, R. (2002). Plant adaptation to low atmospheric pressures: Potential molecular responses. Life Support \& Biosphere Science, 8, 93-101.

Fox, J., Weisberg, S., Price, B., Friendly, M., Firth, D., \& Taylor, S. (2019). Package 'effects'.

Frei, E. R., Ghazoul, J., Matter, P., Heggli, M., \& Pluess, A. R. (2014). Plant population differentiation and climate change: Responses of grassland species along an elevational gradient. Global Change Biology, 20(2), 441-455. https://doi.org/10.1111/gcb.12403

Glesener, R. R., \& Tilman, D. (1978). Sexuality and the components of environmental uncertainty: Clues from geographic parthenogenesis in terrestrial animals. The American Naturalist, 112(986), 659-673. https://doi.org/10.1086/283308

Halbritter, A. H., Fior, S., Keller, I., Billeter, R., Edwards, P. J., Holderegger, R., Karrenberg, S., Pluess, A. R., Widmer, A., \& Alexander, J. M.
(2018). Trait differentiation and adaptation of plants along elevation gradients. Journal of Evolutionary Biology, 31(6), 784-800. https://doi. org/10.1111/jeb.13262

Halekoh, U., \& Højsgaard, S. (2014). A Kenward-Roger approximation and parametric bootstrap methods for tests in linear mixed models The R package pbkrtest. Journal of Statistical Software, 59(9), 1-32. https://doi.org/10.18637/jss.v059.i09

Hartmann, T. (2007). From waste products to ecochemicals: Fifty years research of plant secondary metabolism. Phytochemistry, 68, 28312846. https://doi.org/10.1016/j.phytochem.2007.09.017

He, C., Davies, F. T., \& Lacey, R. E. (2007). Separating the effects of hypobaria and hypoxia on lettuce: Growth and gas exchange. Physiologia Plantarum, 131(2), 226-240. https://doi. org/10.1111/j.1399-3054.2007.00946.x

He, C., Davies, F. T., Lacey, R. E., Drew, M. C., \& Brown, D. L. (2003). Effect of hypobaric conditions on ethylene evolution and growth of lettuce and wheat. Journal of Plant Physiology, 160(11), 1341-1350. https://doi.org/10.1078/0176-1617-01106

He, C., Jacobo-Velázquez, D. A., Cisneros-Zevallos, L., \& Davies, F. T. (2013). Hypobaria and hypoxia affects phytochemical production, gas exchange, and growth of lettuce. Photosynthetica, 51(3), 465473. https://doi.org/10.1007/s11099-013-0047-9

Hervé, M. (2018). Package 'RVAideMemoire'.

Hörandl, E. (2006). The complex causality of geographical parthenogenesis. New Phytologist, 171(3), 525-538. https://doi. org/10.1111/j.1469-8137.2006.01769.x

Huang, W., Bont, Z., Hervé, M. R., Robert, C. A. M., \& Erb, M. (2019). Impact of seasonal and temperature-dependent variation in root defense metabolites on herbivore preference in Taraxacum officinale. Journal of Chemical Ecology, 46(1), 63-75. https://doi.org/10.1007/ s10886-019-01126-9

Huber, M., Bont, Z., Fricke, J., Brillatz, T., Aziz, Z., Gershenzon, J., \& Erb, M. (2016). A below-ground herbivore shapes root defensive chemistry in natural plant populations. Proceedings of the Royal Society B: Biological Sciences, 283, 1-10. https://doi.org/10.1098/rspb.2016.0285

Huber, M., Epping, J., Schulze Gronover, C., Fricke, J., Aziz, Z., Brillatz, T., Swyers, M., Köllner, T. G., Vogel, H., Hammerbacher, A., TriebwasserFreese, D., Robert, C. A. M., Verhoeven, K., Preite, V., Gershenzon, J., $\&$ Erb, M. (2016). A latex metabolite benefits plant fitness under root herbivore attack. PLoS Biology, 14, 1-27. https://doi.org/10.1371/ journal.pbio.1002332

Huber, M., Triebwasser-Freese, D., Reichelt, M., Heiling, S., Paetz, C., Chandran, J. N., Bartram, S., Schneider, B., Gershenzon, J., \& Erb, M. (2015). Identification, quantification, spatiotemporal distribution and genetic variation of major latex secondary metabolites in the common dandelion (Taraxacum officinale agg.). Phytochemistry, 115, 89-98. https://doi.org/10.1016/j.phytochem.2015.01.003

lacobucci, D., Schneider, M. J., Popovich, D. L., \& Bakamitsos, G. A. (2016). Mean centering helps alleviate 'micro' but not 'macro' multicollinearity. Behavior Research Methods, 48(4), 1308-1317. https:// doi.org/10.3758/s13428-015-0624-x

Iwabuchi, K., Goto, E., \& Takakura, T. (1996). Germination and growth of spinach under hypobaric conditions. Environment Control in Biology, 34(3), 169-178. https://doi.org/10.2525/ecb1963.34.169

Iwabuchi, K., \& Kurata, K. (2003). Short-term and long-term effects of low total pressure on gas exchange rates of spinach. Advances in Space Research, 31(1), 241-244. https://doi.org/10.1016/S0273 -1177(02)00743-3

Jump, A. S., \& Peñuelas, J. (2005). Running to stand still: Adaptation and the response of plants to rapid climate change. Ecology Letters, 8(9), 1010-1020. https://doi.org/10.1111/j.1461-0248.2005.00796.x

Kammer, P. M., Steiner, J. S., \& Schöb, C. (2015). Arabis alpina and Arabidopsis thaliana have different stomatal development strategies in response to high altitude pressure conditions. Alpine Botany, 125(2), 101-112. https://doi.org/10.1007/s00035-015-0152-4 
Kearney, M. (2005). Hybridization, glaciation and geographical parthenogenesis. Trends in Ecology \& Evolution, 20(9), 495-502. https://doi. org/10.1016/j.tree.2005.06.005

Keller, S. R., Sowell, D. R., Neiman, M., Wolfe, L. M., \& Taylor, D. R. (2009). Adaptation and colonization history affect the evolution of clines in two introduced species. New Phytologist, 183(3), 678-690. https:// doi.org/10.1111/j.1469-8137.2009.02892.x

Kessler, A., \& Baldwin, I. T. (2001). Defensive function of herbivoreinduced plant volatile emissions in nature. Science, 291(5511), 21412144. https://doi.org/10.1126/science.291.5511.2141

Kessler, A., \& Kalske, A. (2018). Plant secondary metabolite diversity and species interactions. Annual Review of Ecology, Evolution, and Systematics, 49, 115-138. https://doi.org/10.1146/annurev-ecolsys-110617-062406

Kiss, J. Z., Wolverton, C., Wyatt, S. E., Hasenstein, K. H., \& van Loon, J. J. W. A. (2019). Comparison of microgravity analogs to spaceflight in studies of plant growth and development. Frontiers in Plant Science, 10(December), 1-10. https://doi.org/10.3389/fpls.2019.01577

Konno, K. (2011). Plant latex and other exudates as plant defense systems: Roles of various defense chemicals and proteins contained therein. Phytochemistry, 72(13), 1510-1530. https://doi.org/10.1016/j.phyto chem.2011.02.016

Kooyers, N. J., Greenlee, A. B., Colicchio, J. M., Oh, M., \& Blackman, B. K. (2015). Replicate altitudinal clines reveal that evolutionary flexibility underlies adaptation to drought stress in annual Mimulus guttatus. New Phytologist, 206(1), 152-165. https://doi.org/10.1111/ nph.13153

Kuznetsova, A., Brockhoff, P. B., \& Christensen, R. H. B. (2017). ImerTest package: Tests in linear mixed effects models. Journal of Statistical Software, 82(13), 1-26. https://doi.org/10.18637/jss.v082.i13

Levine, L. H., Bisbee, P. A., Richards, J. T., Birmele, M. N., Prior, R. L., Perchonok, M., Dixon, M., Yorio, N. C., Stutte, G. W., \& Wheeler, R. M. (2008). Quality characteristics of the radish grown under reduced atmospheric pressure. Advances in Space Research, 41(5), 754-762. https://doi.org/10.1016/j.asr.2007.03.082

Menken, S. B. J., Smit, E., \& Den Nijas, H. C. M. (1995). Genetic population structure in plants: Gene flow between diploid sexual and triploid asexual dandelions (Taraxacum section ruderalia). Evolution, 49(6), 1108-1118. https://doi.org/10.1111/j.1558-5646.1995.tb04437.x

Metlen, K. L., Aschehoug, E. T., \& Callaway, R. M. (2009). Plant behavioural ecology: Dynamic plasticity in secondary metabolites. Plant, Cell and Environment, 32(6), 641-653. https://doi. org/10.1111/j.1365-3040.2008.01910.x

Meyer, S. E., \& Carlson, S. L. (2001). Achene mass variation in Ericameria nauseosus (Asteraceae) in relation to dispersal ability and seedling fitness. Functional Ecology, 15(2), 274-281. https://doi. org/10.1046/j.1365-2435.2001.00520.x

Michalet, R., Schöb, C., Lortie, C. J., Brooker, R. W., \& Callaway, R. M. (2014). Partitioning net interactions among plants along altitudinal gradients to study community responses to climate change. Functional Ecology, 28(1), 75-86. https://doi.org/10.1111/1365-2435.12136

Midolo, G., \& Wellstein, C. (2020). Plant performance and survival across transplant experiments depend upon temperature and precipitation change along elevation. Journal of Ecology, 108(5), 2107-2120. https://doi.org/10.1111/1365-2745.13387

Moles, A. T., Peco, B., Wallis, I. R., Foley, W. J., Poore, A. G. B., Seabloom, E. W., Vesk, P. A., Bisigato, A. J., Cella-Pizarro, L., Clark, C. J., Cohen, P. S., Cornwell, W. K., Edwards, W., Ejrnæs, R., Gonzales-Ojeda, T., Graae, B. J., Hay, G., Lumbwe, F. C., Magaña-Rodríguez, B., ... Hui, F. K. C. (2013). Correlations between physical and chemical defences in plants: Tradeoffs, syndromes, or just many different ways to skin a herbivorous cat? The New Phytologist, 198(1), 252-263. https://doi. org/10.1111/nph.12116

Molina-Montenegro, M., Palma-Rojas, C., Alcayaga-Olivares, Y., Oses, R., Corcuera, L. J., Cavieres, L. A., \& Gianoli, E. (2013). Ecophysiological plasticity and local differentiation help explain the invasion success of Taraxacum officinale (dandelion) in South America. Ecography, 36(6), 718-730. https://doi.org/10.1111/j.1600-0587.2012.07758.x

Moore, B. D., Andrew, R. L., Külheim, C., \& Foley, W. J. (2014). Explaining intraspecific diversity in plant secondary metabolites in an ecological context. The New Phytologist, 201(3), 733-750. https://doi. org/10.1111/nph.12526

Moreira, X., Petry, W. K., Mooney, K. A., Rasmann, S., \& Abdala-Roberts, L. (2018). Elevational gradients in plant defences and insect herbivory: Recent advances in the field and prospects for future research. Ecography, 41(9), 1485-1496. https://doi.org/10.1111/ecog.03184

Mustroph, A., Barding, G. A., Kaiser, K. A., Larive, C. K., \& Bailey-Serres, J. (2014). Characterization of distinct root and shoot responses to low-oxygen stress in Arabidopsis with a focus on primary C- and Nmetabolism. Plant, Cell and Environment, 37(10), 2366-2380. https:// doi.org/10.1111/pce.12282

Nakabayashi, R., \& Saito, K. (2015). Integrated metabolomics for abiotic stress responses in plants. Current Opinion in Plant Biology, 24, 10-16. https://doi.org/10.1016/j.pbi.2015.01.003

Neilson, E. H., Goodger, J. Q. D., Woodrow, I. E., \& Møller, B. L. (2013). Plant chemical defense: At what cost? Trends in Plant Science, 18(5), 250-258. https://doi.org/10.1016/j.tplants.2013.01.001

Nicotra, A. B., Atkin, O. K., Bonser, S. P., Davidson, A. M., Finnegan, E. J., Mathesius, U., Poot, P., Purugganan, M. D., Richards, C. L., Valladares, F., \& van Kleunen, M. (2010). Plant phenotypic plasticity in a changing climate. Trends in Plant Science, 15(12), 684-692. https://doi. org/10.1016/j.tplants.2010.09.008

Paul, A.-L., \& Ferl, R. J. (2006). The biology of low atmospheric pressure - Implications for exploration mission design and advanced life support. Gravitational and Space Biology, 19(August), 3-18.

Paul, A. L., Schuerger, A. C., Popp, M. P., Richards, J. T., Manak, M. S., \& Ferl, R. J. (2004). Hypobaric biology: Arabidopsis gene expression at low atmospheric pressure. Plant Physiology, 134(1), 215-223. https:// doi.org/10.1104/pp.103.032607

Pellissier, L., Roger, A., Bilat, J., \& Rasmann, S. (2014). High elevation Plantago lanceolata plants are less resistant to herbivory than their low elevation conspecifics: Is it just temperature? Ecography, 37(10), 950-959. https://doi.org/10.1111/ecog.00833

Pichersky, E., \& Gershenzon, J. (2002). The formation and function of plant volatiles: Perfumes for pollinator attraction and defense. Current Opinion in Plant Biology, 5(3), 237-243. https://doi. org/10.1016/S1369-5266(02)00251-0

R Core Team. (2017). R: A language and environment for statistical computing. R Foundation for Statistical Computing. https://doi. org/10.1007/978-3-540-74686-7

Ramakrishna, A., \& Ravishankar, G. A. (2011). Influence of abiotic stress signals on secondary metabolites in plants. Plant Signaling and Behavior, 6(11), 1720-1731. https://doi.org/10.4161/ psb.6.11.17613

Rasmann, S., Buri, A., Gallot-Lavallée, M., Joaquim, J., Purcell, J., \& Pellissier, L. (2014). Differential allocation and deployment of direct and indirect defences by Vicia sepium along elevation gradients. Journal of Ecology, 102(4), 930-938. https://doi.org/10.1111/1365-2745.12253

Richards, J. T., Corey, K. A., Paul, A. L., Ferl, R. J., Wheeler, R. M., \& Schuerger, A. C. (2006). Exposure of Arabidopsis thaliana to hypobaric environments: Implications for low-pressure bioregenerative life support systems for human exploration missions and terraforming on Mars. Astrobiology, 6(6), 851-866. https://doi.org/10.1089/ ast.2006.6.851

Sandoya, V., Pauchard, A., \& Cavieres, L. A. (2017). Natives and nonnatives plants show different responses to elevation and disturbance on the tropical high Andes of Ecuador. Ecology and Evolution, 7(19), 7909-7919. https://doi.org/10.1002/ece3.3270

Schliemann, W., Ammer, C., \& Strack, D. (2008). Metabolite profiling of mycorrhizal roots of Medicago truncatula. Phytochemistry, 69(1), 112146. https://doi.org/10.1016/j.phytochem.2007.06.032 
Semchenko, M., Saar, S., \& Lepik, A. (2014). Plant root exudates mediate neighbour recognition and trigger complex behavioural changes. New Phytologist, 204(3), 631-637. https://doi.org/10.1111/nph.12930

Smith, W. K., \& Geller, G. N. (1979). Plant transpiration at high elevations: Theory, field measurements, and comparisons with desert plants. Oecologia, 41(1), 109-122. https://doi.org/10.1007/BF00344841

Spanarkel, R., \& Drew, M. C. (2002). Germination and growth of lettuce (Lactuca sativa) at low atmospheric pressure. Physiologia Plantarum, 116(4), 468-477. https://doi.org/10.1034/j.1399-3054.2002.11604 05.x

Stevenson, P. C., Nicolson, S. W., \& Wright, G. A. (2017). Plant secondary metabolites in nectar: Impacts on pollinators and ecological functions. FunctionalEcology,31,65-75.https://doi.org/10.1111/1365-2435.12761

Stewart-Wade, S. M., Neumann, S., Collins, L. L., \& Boland, G. J. (2002). The biology of Canadian weeds. 117. Taraxacum officinale G. H. Weber ex Wiggers. Canadian Journal of Plant Science, 82, 825-853.

Sultan, S. E. (2000). Phenotypic plasticity for plant development, function and life history. Trends in Plant Science, 5(12), 537-542. https:// doi.org/10.1016/S1360-1385(00)01797-0

Tackenberg, O., Poschlod, P., \& Kahmen, S. (2003). Dandelion seed dispersal: The horizontal wind speed does not matter for long-distance dispersal - It is updraft! Plant Biology, 5, 451-454. https://doi. org/10.1055/s-2003-44789

Tang, Y., Gao, F., Guo, S., \& Li, F. (2015). The morphology, physiology and nutritional quality of lettuce grown under hypobaria and hypoxia. Acta Astronautica, 112, 29-36. https://doi.org/10.1016/j.actaa stro.2015.03.005

Terashima, I., Masuzawa, T., Ohba, H., \& Yokoi, Y. (1995). Is photosynthesis suppressed at higher elevations due to low $\mathrm{CO}_{2}$ pressure? Ecology, 76(8), 2663-2668. https://doi.org/10.2307/2265838

Tilquin, A., \& Kokko, H. (2016). What does the geography of parthenogenesis teach us about sex? Philosophical Transactions of the Royal Society of London. Series B, Biological Sciences, 371(1706), 2015051620150538. https://doi.org/10.1098/rstb.2015.0538

Van Dijk, P. J., Barrett, S. C. H., \& Vinkenoog, R. (2003). Ecological and evolutionary opportunities of apomixis: Insights from Taraxacum and Chondrilla. Philosophical Transactions of the Royal Society B: Biological Sciences, 358(1434), 1113-1121. https://doi.org/10.1098/ rstb.2003.1302

van Kleunen, M., \& Fischer, M. (2005). Constraints on the evolution of adaptive phenotypic plasticity in plants. The New Phytologist, 166(1), 49-60. https://doi.org/10.1111/j.1469-8137.2004.01296.x

Verduijn, M. H., Van Dijk, P. J., \& Van Damme, J. M. M. (2004). The role of tetraploids in the sexual-asexual cycle in dandelions (Taraxacum). Heredity, 93(4), 390-398. https://doi.org/10.1038/sj.hdy.6800515

Verhoeven, K. J. F., \& Biere, A. (2013). Geographic parthenogenesis and plant-enemy interactions in the common dandelion. BMC Evolutionary Biology, 13(1), 23. https://doi.org/10.1186/1471-2148-13-23

Villaverde, T., González-Moreno, P., Rodríguez-Sánchez, F., \& Escudero, M. (2017). Niche shifts after long-distance dispersal events in bipolar sedges (Carex, Cyperaceae). American Journal of Botany, 104(11), 1765-1774. https://doi.org/10.3732/ajb.1700171
Ward, J. K., Antonovics, J., Thomas, R. B., \& Strain, B. R. (2000). Is atmospheric $\mathrm{CO}_{2}$ a selective agent on model $\mathrm{C} 3$ annuals? Oecologia, 123(3), 330-341. https://doi.org/10.1007/s004420051019

Ward, J. K., \& Strain, B. R. (1997). Effects of low and elevated $\mathrm{CO}_{2}$ partial pressure on growth and reproduction of Arabidopsis thaliana from different elevations. Plant, Cell and Environment, 20(2), 254-260. https://doi.org/10.1046/j.1365-3040.1997.d01-59.x

Wheeler, R. M. (2017). Agriculture for space: People and places paving the way. Open Agriculture, 2(1), 14-32. https://doi.org/10.1515/ opag-2017-0002

Wickham, H. (2016). ggplot2: Elegant graphics for data analysis. Springer-Verlag.

Woodward, F. I., \& Bazzaz, F. A. (1988). The responses of stomatal density to $\mathrm{CO}_{2}$ partial pressure. Journal of Experimental Botany, 39(12), 1771-1781. https://doi.org/10.1093/jxb/39.12.1771

Xu, Z., Jiang, Y., Jia, B., \& Zhou, G. (2016). Elevated- $\mathrm{CO}_{2}$ response of stomata and its dependence on environmental factors. Frontiers in Plant Science, 7, 1-15. https://doi.org/10.3389/fpls.2016.00657

Xu, Z., Jiang, Y., \& Zhou, G. (2015). Response and adaptation of photosynthesis, respiration, and antioxidant systems to elevated $\mathrm{CO}_{2}$ with environmental stress in plants. Frontiers in Plant Science, 6, 1-17. https://doi.org/10.3389/fpls.2015.00701

Zabalza, A., van Dongen, J. T., Froehlich, A., Oliver, S. N., Faix, B., Gupta, K. J., Schmälzlin, E., Igal, M., Orcaray, L., Royuela, M., \& Geigenberger, P. (2009). Regulation of respiration and fermentation to control the plant internal oxygen concentration. Plant Physiology, 149(2), 10871098. https://doi.org/10.1104/pp.108.129288

Zhou, M., Callaham, J. B., Reyes, M., Stasiak, M., Riva, A., Zupanska, A. K., Dixon, M. A., Paul, A.-L., \& Ferl, R. J. (2017). Dissecting low atmospheric pressure stress: Transcriptome responses to the components of hypobaria in Arabidopsis. Frontiers in Plant Science, 8, 1-13. https:// doi.org/10.3389/fpls.2017.00528

Züst, T., Heichinger, C., Grossniklaus, U., Harrington, R., Kliebenstein, D. J., \& Turnbull, L. A. (2012). Natural enemies drive geographic variation in plant defenses. Science, 338, 116-120. https://doi.org/10.1126/ science. 1226397

\section{SUPPORTING INFORMATION}

Additional supporting information may be found online in the Supporting Information section.

How to cite this article: Arce, C. C. M., Bont, Z., Machado, R. A. R., Cristaldo, P. F., \& Erb, M. (2021). Adaptations and responses of the common dandelion to low atmospheric pressure in high-altitude environments. Journal of Ecology, 109, 3487-3501. https://doi.org/10.1111/1365-2745.13736 